
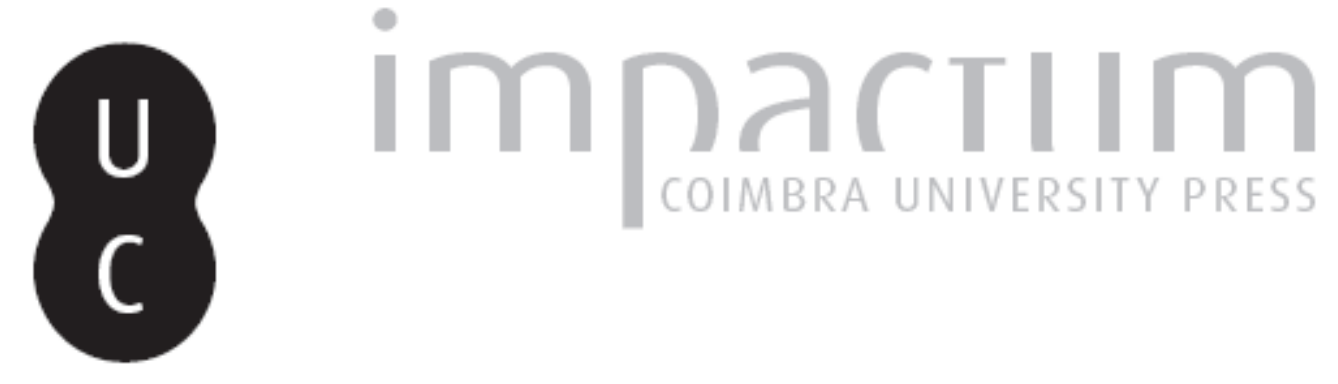

\title{
Apectos da responsabilidade no Instituto da Cidadania Europeia
}

Autor(es): $\quad$ Farias, Eduardo Pimentel de

Publicado por: Centro de Informação Europe Direct de Aveiro; Centro de Estudos

URL

persistente: Interdisciplinares do Século XX

DOI:

URI:http://hdl.handle.net/10316.2/33980

Accessed : $\quad$ 26-Apr-2023 10:00:11

DOI:http://dx.doi.org/10.14195/1647-6336_11_9

A navegação consulta e descarregamento dos títulos inseridos nas Bibliotecas Digitais UC Digitalis, UC Pombalina e UC Impactum, pressupõem a aceitação plena e sem reservas dos Termos e Condições de Uso destas Bibliotecas Digitais, disponíveis em https://digitalis.uc.pt/pt-pt/termos.

Conforme exposto nos referidos Termos e Condições de Uso, o descarregamento de títulos de acesso restrito requer uma licença válida de autorização devendo o utilizador aceder ao(s) documento(s) a partir de um endereço de IP da instituição detentora da supramencionada licença.

Ao utilizador é apenas permitido o descarregamento para uso pessoal, pelo que o emprego do(s) título(s) descarregado(s) para outro fim, designadamente comercial, carece de autorização do respetivo autor ou editor da obra.

Na medida em que todas as obras da UC Digitalis se encontram protegidas pelo Código do Direito de Autor e Direitos Conexos e demais legislação aplicável, toda a cópia, parcial ou total, deste documento, nos casos em que é legalmente admitida, deverá conter ou fazer-se acompanhar por este aviso.

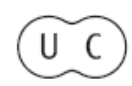


DEBATER

A EUROPA

jul-dez 2014

QUE EUROPA(S)?

CONTEXTOS E DESAFIOS 


\section{Apectos da Responsabilidade no Instituto da Cidadania Europeia}

Eduardo Pimentel de Farias

Doutorando da FDUC

E-mail: eduardopimentelf@hotmail.com

\section{Resumo}

$\mathrm{Na}$ via contrária ao processo de diminuição ou de regionalização do mundo, o Instituto da Responsabilidade se expande e revela-se como a mais emblemática expressão de juridicidade do Direito, quer seja no seu âmbito interno, internacional ou mesmo comunitário, onde aliás, as necessidades de garantia se fazem urgentes. Pensando nisto, propomos um estudo sucinto do tema da Responsabilidade no Direito Europeu, utilizando a cidadania comunitária como agente delimitador e fio condutor para uma construção argumentativa equilibrada e propulsora de debate. Assim, a ideia matriz da Responsabilidade será apresentada de forma diluída ao conteúdo dos direitos de livre circulação e permanência, de proteção diplomática, de participação política eleitoral e de acesso institucional conferidos ao cidadão da União, num verdadeiro processo de interseção criativa entre dois dos tópicos mais debatidos da atualidade. Convém destacar, todavia, que este trabalho não se direciona a análises de situações ferozmente criticáveis a respeito da responsabilidade ou da falta dela no Direito Comunitário. Em contra partida, mais do que uma mera compilação de ideias e considerações sobre a temática da Responsabilidade, este trabalho termina por ressaltar a tendência doutrinária para uma avaliação macroscópica do assunto, visualizando a responsabilidade enquanto ética necessária e solidária destinada a intensificar o instituto da personalidade.

Palavras-chave: União Europeia; Responsabilidade; Cidadania Europeia 


\begin{abstract}
In the opposite direction to the decrease or regionalization process of the world, the Office of Accountability expands and reveals itself as the most emblematic expression of legality of law, either in its domestic, international or even Community framework, where warranty needs are urgent. Thinking about this, we propose a brief study of the subject of Liability in European Law, using community citizenship as a bounding agent and conductor for a balanced argumentative debate. Thus, the idea of the Responsibility Matrix will be presented in a diluted form to the content of the rights of free movement and residence, diplomatic protection, electoral political participation and institutional access conferred to Union citizens, in a true process of creative intersection between two of the topics most debated today. I tis worth noting, however, that this work does not address to analysis fiercely questionable in relation to situations regarding responsibility/accountability or lack there of it in EC law. In return, more than a mere compilation of ideas and considerations on the issue of liability, this paper ends by noting the doctrinal tendency for a macroscopic evaluation of the subject, viewing the responsibility as needed ethics and solidarity aimed at intensifying the Institute of Personality .
\end{abstract}

Keywords: Responsibility; accountability; Community; Citizenship

\title{
Nota Introdutória
}

Este texto propõe reunir considerações relevantes ao tema da Responsabilidade no Direito Europeu. Para isso, utiliza do instituto da Cidadania Comunitária como agente delimitador e fio condutor da sua construção argumentativa.

A idéia matriz da Responsabilidade, portanto, será apresentada de forma diluída ao conteúdo dos direitos de circulação e permanência, de proteção diplomática, de participação política eleitoral e de acesso institucional conferidos ao cidadão da União. Desta forma, pretende-se criar uma verdadeira interseção criativa entre dois dos tópicos mais debatidos da atualidade.

Convém destacar, todavia, que este trabalho não se direciona à análise das críticas a respeito da responsabilidade ou da falta dela no Direito Comunitário. Busca-se aqui, 
inversamente, uma observação macroscópica, a olho nú e mais direcionada aos tópicos relacionados ao conceito do indivíduo enquanto cidadão europeu.

\section{I-Responsabilidade e Cidadania Europeia}

Os acontecimentos políticos encenados no final da década de oitenta e início dos anos noventa do século passado promoveram o rompimento definitivo com a antiga ordem mundial estabelecida. Sob os escombros emblemáticos do Muro de Berlim a Alemanha se reunificou. Enquanto isso, o sistema soviético foi desmantelado e repartido numa gama de novas repúblicas independentes ao passo que os norte-americanos se fortaleceram como nação hegemônica e alicerce para a nova ordem unipolar.

No plano comunitário, o Ato Único de 1986 não havia somente revigorado a ideia de Europa mas também a prioridade dos Estados-membros na formação de um espaço de fruição plena das liberdades ${ }^{1}$. Contudo, a manifesta falta de estabilidade política, principalmente no eixo leste-oeste, reinstaurou o debate e acelerou as negociações para um novo tratado europeu resultante da conjugação de interesses econômicos, monetários e políticos²

\footnotetext{
1 “A adopção do Acto único resultou da conjugação de uma pluralidade de factores que determinaram a oportunidade e conveniência de uma revisão formal do quadro constitutivo das Comunidades Européias. De entre os motivos que destacavam-se: os bloqueios que caracterizavam o processo de decisão em virtude da regra do consenso; a pretensão do Parlamento Europeu, eleito por sufrágio directo desde 1979, de ver aumentada a sua participação no processo político comunitário; a aprovação pelo Parlamento Europeu em 1984 de um Projecto de Tratado de União Européia, que havia colocado a revisão dos tratados na agenda política; a eleição de Delors para Presidente da Comissão, em 1985, determinado a conferir novo impulso à integração européia; e o termo de um longo ciclo de recessão económica internacional, provocado pelo impacto dos choques petrolíferos na década de 70. O Acto Único Europeu constitui a primeira reforma geral dos Tratados operada desde o início das três Comunidades. Designou-se "único" porque através do mesmo acto normativo os Estados-membros procederam à revisão dos três Tratados constitutivos das diferentes Comunidades Européias e concordaram, ainda, em institucionalizar a chamada Cooperação Política Européia." SOARES, António Goucha- A União Européia,p.2122.

${ }^{2}$ Sobre o derradeiro lapso histórico, Maria Manuela Tavares Ribeiro, discorre, apresentando os devidos questionamentos a fim de bem redefinir os caminhos da autonomia européia tomados a partir de então: "A verdade, porém, é que nos anos de 1989-1992, marcaram uma ruptura na história da Europa. Impor-se-á, para melhor esclarecimento desta afirmação, relembrar a queda do Muro de Berlim (1989), a reunificação alemã (1990), a desagregação da União Soviética (1991) e a independência de suas várias repúblicas, a criação da Comunidade dos Estados Independentes (CEI), a formação da Federação da Rússia (presidida por Boris Ieltsin), a crise da ex-Jugoslávia, a desestabilização da "ordem mundial" com a guerra do Golfo. Perante este panorama, no Ocidente, os Estados da Comunidade Económica Européia procuraram o equilíbrio e a estabilidade. Por outras palavras, dinamizaram-se novas e várias formas de cooperação Este-Oeste que o Conselho da Europa coordena através de uma política activa de abertura aos países do Leste. A unificação alemã representava, todavia, um desafio para a Comunidade. Não significava a hegemonia alemã um sério risco para a integração comunitária? Ou, a invés, a integração européia e a unificação alemã eram duas faces de uma só medalha, como afirmou
} 
Assim, em 7 de fevereiro de 1992 o Tratado de Maastricht aprova a mais importante reforma dos tratados fundadores da Comunidade ao introduzir o conceito de União Européia no acervo comunitário, além de reforçar os interesses dos nacionais e dos seus Estadosmembros mediante a instituição de uma cidadania da União. Nesses termos, o Tratado da União encoraja a uma verdadeira ruptura, ou melhor, a um redimensionamento da condição e relevância da pessoa humana frente ao processo de integração. Para Maastricht, o indivíduo deve ser tido como elemento indispensável à sustentação do projeto comunitário ${ }^{3}$.

Apesar disso, a crítica doutrinária ainda identifica uma certa fragilidade nesse novo conceito de cidadania da União. Para essa doutrina, a dependência entre o estatuto de cidadão comunitário e a titularidade de nacional de um dos Estados-membros afasta o Tratado do cunho decisório dos sujeitos que serão ou não beneficiários do instituto. De fato, o Tratado de Maastricht não estabelece um reconhecimento autônomo da cidadania comunitária. Isto é, o Tratado opta pelo critério da subordinação para introduzir o instituto da cidadania no acervo comunitário, o que significa dizer que "é cidadão da União qualquer pessoa que tenha a nacionalidade de um Estado-membro"4.

Mas afastadas as condições remissivas para o reconhecimento da cidadania européia, cumpre mencionar que o legislador comunitário dispõe que "os cidadãos da União gozam de direitos e estão sujeitos a deveres previstos nos Tratados" ${ }^{\prime 5}$ E apesar dessa previsão normativa se referir a um extensivo número de direitos atinentes ao instituto da cidadania da União, tanto de ordem adjetiva quanto em matéria substantiva, parece mais oportuno seguir a corrente que limita a compilação de direitos às prerrogativas que versem exclusivamente sobre a condição de cidadão europeu. Nesse sentido, entre os direitos referenciados como acervo

Helmunt Kohl? Neste quadro, as negociações do Tratado de União Européia aceleravam-se e do diálogo persuasivo e insistente de Mitterrand-Kohl resultou um mútuo convencimento do interesse em ligar o princípio da União Económica e monetária e da união política. Seria este um meio de "esconjurar" os nacionalismos efevercentes?; uma forma de conter a preeminência alemã na comunidade?;ou ainda um laço de fortalecimento numa comunidade européia alargada? Em suma, representaria a União Européia o desejado pólo de estabilidade?in A idéia de Europa-Uma perspectiva histórica,p.72.

3 "Com o tratado de Maastricht, opera-se uma transformação qualitativa do estatuto comunitário dos cidadãos dos Estados-membros(...).Nos termos exactos do artigo $8^{\circ}$, a única condição para ser cidadão da União é ser cidadão de um Estado-membro. Por consequiência, nasce um estatuto, que envolve um conjunto de direitos cujo exercício já não pode depender da verificação de requisitos de natureza económica. Em definitivo, o agente económico cedeu lugar ao cidadão". DUARTE, Maria Luísa-Estudos de Direito da União e das Comunidades EuropéiasDireito Comunitário Institucional, União Européia e Constituição, Direito Comunitário Material, p.246-247.

4 Artigo $20^{\circ}$ do Tratado sobre o Funcionamento da União Europeia e Artigo $9^{\circ}$ do Tratado da União Europeia.

${ }^{5}$ Segunda parte do Artigo $20^{\circ}$ do Tratado sobre Funcionamento da União Européia. 
definitivamente interligado ao contexto da cidadania européia, salientaremos neste texto o direito de livre circulação e permanência; de proteção diplomática; de participação política ao nível autárquico e comunitário e de acesso às instituições da União ${ }^{6}$.

\subsection{O Direito de Circular e Permanecer e a Responsabilidade do Estado- membro por violação do Direito Comunitário.}

O Direito de circular e permanecer livremente no território de qualquer Estado-membro é fruto de um longo processo evolutivo movido em parceria com as instituições jurisdicionais e legislativas comunitárias. Aliás, o envolvimento dessas instituições no sentido de oxigenar e liberalizar as vias de contato entre os indivíduos e a Comunidade foi substancial para a trasposição dos obstáculos dos tratados fundadores. A Comissão, por exemplo, lançou desde cedo uma proposta de diretiva com o objetivo de atrelar a liberdade de residência à liberdade de circulação. Enquanto isso, no mesmo período, o Tribunal de Justiça trabalha a flexibilização do fundamento legal adstrito à liberdade de circulação ao considerar turistas como destinatários de serviços e logo agentes do composto econômico funcional. ${ }^{7}$

O direito de circular e permanecer na União, porém, só foi oficialmente reconhecido a todo e qualquer cidadão europeu, independentemente do nexo mercadológico, a partir do Tratado de Maastricht. De fato, esse Tratado foi decisivo para o estabelecimento do conteúdo autônomo da liberdade de circular e permanecer. Mas, também demonstrou um entendimento estático ao optar pela manutenção do conjunto de restrições de ordem pública, saúde e segurança derivadas de acordos inter-governamentais. ${ }^{8}$ Aliás, a manutenção dessas limitações previstas em outros tratados e nas disposições adotadas em sua aplicação instigou o

\footnotetext{
${ }^{6}$ Nesse trabalho não será abordado o direito de iniciativa reconhecido pelo Tratado de Lisboa. Esse direito garante que um milhão, pelo menos, de cidadãos da União, nacionais de um número significativo de EstadosMembros, poderem convidar a Comissão Europeia a apresentar propostas legislativas nos domínios da sua competência.

${ }^{7}$ Acórdão Luisi e Carbone c. Ministero Del Tesoro- o processo 268/82 e 26/83.

8 "Segundo a jurisprudência do TJ, estas restrições devem ser interpretadas restritivamente. Assim, o TJ afirmou que a noção de ordem pública no contexto comunitário e, nomeadamente, enquanto justificação de uma derrogação ao princípio fundamental da livre circulação de trabalhadores deve ser entendida restritivamente, de forma que seu alcance não pode ser determinado unilateralmente por cada um dos Estados membros sem controlo dos órgãos comunitários. Todavia, como não existe um "código uniforme de valores" acabam por ser os Estados a determinar o que entendem por ordem pública e segurança pública, isto é, a sua margem de manobra permanece bastante ampla, embora dentro de certos limites". MARTINS, Ana Maria Guerra-Curso de Direito Constitucional da União Européia,p.559-560.
} 
surgimento de correntes doutrinárias e posturas jurisdicionais defensivas de um esvaziamento de efeito direto para esta norma comunitária. Em outras palavras, a tese dominante indica que o direito narrado no atual artigo $21^{\circ}$ do Tratado sobre o Funcionamento da União não apresenta qualquer conteúdo inovador fundamental para a articulação de um efeito direto ${ }^{9} . \mathrm{Ou}$ seja, o direito vigente conferido ao cidadão europeu para transitar e permanecer no espaço comunitário poderia ser melhor compreendido como uma ratificação das liberdades já reconhecidas pelo corpo jurídico operante.

Com o objetivo de evitar o incumprimento da norma comunitária e a conseqüente desproteção dos particulares em virtude da evocação de argumentos como este, o Tribunal de Justiça vem reconhecendo o direito subjetivo à reparação decorrente da não transposição de uma diretiva desprovida de efeito direto. Para o Tribunal, o princípio da responsabilidade do Estado surge atrelado à obrigação de cooperação mútua. Assim, o direito de reparação deve ser considerado justamente em decorrência da impossibilidade de invocação da norma comunitária pelo particular lesado.

Cumpre destacar, porém, que a incidência do princípio da responsabilidade não é automática e fundamentada apenas no desprovimento de efeito direto da norma violada. Antes de mais, o Tribunal de Justiça entende que deverá haver uma verificação restrita a respeito do resultado da diretiva para verificar se a mesma pretendia efetivamente conferir direitos reais aos particulares. Além disso, para o Tribunal, importa conferir o conteúdo desses direitos, assim como o nexo causal estabelecido entre o prejuízo e o descumprimento da obrigação de transposição. ${ }^{10}$

Inicialmente referenciado no Acórdão Francovich ${ }^{11}$, o tema da responsabilidade do Estado-membro e o conjunto de requisitos necessários à sua responsabilização foram reavaliados e aprofundados pelo Tribunal de Justiça no julgamento do processo Brasserie du Pêcheur. ${ }^{12}$ Nesse último caso, porém, foi salientada a necessidade de uma apreciação caracterizada da violação. Isto é, da análise de critérios paralelos para se esclarecer a gravidade e a configuração do dano. Assim, o Tribunal entende que o processo de

\footnotetext{
${ }^{9}$ Ver Artigo 3, $\mathrm{n}^{\circ} 2$ do Tratado da União Europeia

${ }^{10}$ Sobre esta temática, ver: RIBEIRO DA CUNHA, Marta C.- Da responsabilidade do Estado pela violação do direito comunitário.

${ }^{11}$ Acórdão Andréa Francovich e o.c. República Italiana, de 19/11/1991, Proc. C-6/90 e C-9/90.

${ }^{12}$ Acórdão Brasserie du Pêcheur AS c. RFA e The Queen c. Secretary of state for transport, de 5/3/96,Proc. C$46 / 93$ e C-48/93.
} 
responsabilização por violação e incumprimento estatal deve responder a critérios que vão desde à apreciação da margem das autoridades nacionais, ao grau de clareza e precisão da norma violada, à intencionalidade do incumprimento ou do prejuízo, à despulpabilidade ou não de eventual erro de direito e até à contribuição dos órgãos comunitários.

Por fim, ainda resta afirmar que cabe à ordem jurídica nacional a tarefa de processar e julgar as demandas relativas a este princípio. Ou seja, apesar do seu reconhecimento substantivo emanar do Direito Comunitário, incumbe ao regime processual dos Estadosmembros o dever de promoção das condições necessárias à perfeita fruição da ação. Tudo isso, em conformidade com as garantias firmadas para reclamações semelhantes no direito interno.

\subsection{A Responsabilidade e o Direito de Proteção Diplomática e Consular Comunitária.}

De forma didática, o direito comunitário de proteção diplomática e consular se caracteriza pela possibilidade conferida ao cidadão deslocado em um país terceiro e sem representação do seu Estado original para requerer a proteção das autoridades consulares e diplomáticas de qualquer Estado-membro. Devendo-se ainda se submeter aos mesmos critérios de avaliação discricionária a que os nacionais deste Estado estariam subordinados ${ }^{13}$.

Assim, é condição básica para o exercício desta prerrogativa que o sujeito esteja deslocado, ou melhor, que o cidadão se encontre em território do qual não faz parte a União Européia. Nesse sentido, ao contrário dos outros direitos da cidadania comunitária, a proteção diplomática e consular se destaca pela singularidade de só se efetivar na esfera de um terceiro sujeito de direito internacional. ${ }^{14}$ Sem contar, que norma comunitária não prevê que a proteção diplomática e consular seja conferida pela União ou mesmo pelo conjunto de Estadosmembros, mas apenas por qualquer Estado da comunidade. Isso quer dizer, que além desse direito não se exercer nas fronteiras da União também não será adquirido face à mesma, em

\footnotetext{
${ }^{13}$ Ver artigo $23^{\circ}$ do Tratado sobre Funcionamento da União Europeia.

14 "Diferentemente dos direitos que acabámos de analisar, não se trata aqui de direitos a exercer face à União ou sequer no interior da União. A protecção diplomática ou consular caracteriza-se pelo facto de constituir uma forma de tutela dos indivíduos perante terceiros que sejam dotados de personalidade jurídica internacional. E a faculdade de que possam beneficiar os titulares da cidadania da União resulta da necessidade de prover à protecção de um cidadão, no território de um país terceiro, quando o Estado de que ele é nacional aí se não encontre representado". MOURA RAMOS, Rui Manuel Gens- A cidadania da União: Caracterização, Conteúdo e Desenvolvimento,p.359.
} 
conformidade com o princípio da representação subsidiária introduzida nas negociações para Maastricht. $^{15}$

Nesses termos, o legislador comunitário cria um direito não self-executing, pois absolve a União das responsabilidades de garantia e dos deveres de negociação. A determinação da forma e das modalidades de assistência a que se pretende caberá, portanto, ao conjunto dos Estados-membros. Devendo-se mencionar, que permanece reservado ao foro particular de cada Estado indivuidualmente requisitado o conteúdo discricionário da sua resposta. Exigindo-se, contudo, atenção especial ao cumprimento e respeito do requisito da igualdade de tratamento entre os nacionais e cidadãos de outros Estados-membros a fim de fortalecer o princípio da assimilação e alargar os horizontes do processo integrativo ${ }^{16}$.

Nesse compasso, caberá a cada Estado-membro, de forma particular e independente da União, a faculdade discricionária de exercício e de renúncia da prerrogativa. O que explica grande parte da crítica doutrinária que não reconhece no instituto da proteção diplomática um verdadeiro direito de cidadania. Para eles, indivíduos e sociedades não gozam do direito de reclamar proteção diplomática ao seu próprio Estado ou à qualquer outro. Este exercício estaria verdadeiramente condicionado às questões políticas, conjunturais e, em grande medida, às leis existentes ou recursos disponíveis ${ }^{17}$.

Assim, até quando se leva em conta a evolução do Direito Internacional dos Direitos Humanos a sugestão de um dever de cooperação na promoção desta espécie de proteção acaba por ceder frente às exigências de interesses mais producentes à generalidade dos restantes ${ }^{18}$.

\footnotetext{
${ }^{15}$ KOVAR/SIMON-La Citoyenneté Européene, p.312.

16 "Este direito beneficia especialmente os nacionais dos Estados membros que, como Portugal, têm poucas representações diplomáticas e consulares em Estados terceiros, particularmente em pequenos Estados, ou em Estados longínquos, da África, da Ásia, da América ou da Oceania, e que, desta forma, podem beneficiar, nesses Estados terceiros, da protecção diplomática e consular de Estados membros como o Reino Unido, a França e a Alemanha, que se encontram representadas por embaixadas em quase todos os Estados da Comunidade Internacional e possuem uma vasta rede de consulados". QUADROS, Fausto de-Direito da União EuropeiaDireito Constitucional e Administrativo da União Europeia, p.120

17 “Todavia, a questão de se saber em que medida um Estado pode exercer a sua protecção diplomática releva mais do direito interno dos Estados, ou dos acordos bilaterais que possam existir, do que do próprio direito diplomático, já que em regra, os indivíduos ou as sociedades não gozam do direito de reclamar a protecção do seu próprio Estado, senão sob condições muito específicas e quase de última instância. Efetivamente, o exercício da protecção diplomática decorre, em grande medida, das leis existentes, das condições políticas e conjunturais, e dos próprios recursos disponíveis”. MONGIARDIM, Maria Regina-Diplomacia,p.144

18 “Quando muito, tendo em conta a evolução do Direito Internacional dos Direitos Humanos, que atribui a cada Estado um dever vago de cooperação na sua promoção, faz sentido sustentar que igualmente um Estado tem, até por maioria de razão, um dever desta espécie de proteger os seus nacionais. Mas tal dever é demasiado tênue e vago para não ceder perante exigências decorrentes de outros interesses. Exercer a proteção diplomática de um
} 
Nesse sentido, resta esclarecido que a norma comunitária irresponsabiliza a União e qualquer Estado-membro requisitado do exercício da proteção diplomática de um nacional europeu. Não há, portanto, no sistema jurisdicional comunitário previsão legal específica e relativa a um direito de ação por não cumprimento do pressuposto de proteção diplomática enquanto direito de cidadania. Quando muito, pode-se fazer uma analogia entre esta prerrogativa e alguma situação particular descrita em acordos de pesca de que faz parte a Comunidade ${ }^{19}$. Nesses acordos, autoridades de países terceiros ficam obrigadas a informar à delegação européia local o caso de apresamento de navio de pesca que arvoram pavilhão de um Estadomembro para que essa possa exercer seu dever de proteção diplomática.

No caso Odigitria, por exemplo, uma sociedade de direito helênico interpôs uma ação perante o Tribunal de Primeira Instância das Comunidades com fundamento na suposta falta de cumprimento, por parte da Comissão, dos seus deveres de proteção diplomática a favor do comandante do navio e da própria demandante ${ }^{20}$. Inclusive, esse Acórdão foi recentemente utilizado pela própria Comissão para relançar a discussão sobre a possibilidade de exercício da proteção diplomática através das suas próprias delegações e dentro dos domínios abrangidos pela competência da Comunidade.

Contudo, ainda é na ordem interna de cada Estado que o tema da responsabilidade na proteção diplomática ganha contornos de fato. Ou seja, só o ordenamento jurídico de cada Estado-membro é capaz de responder se a proteção diplomática é um dever daquele Estado ou somente um direito de cidadania. Pode-se antecipar, porém, que se os ordenamentos constitucionais decidem reconhecer aos cidadãos nacionais o direito de proteção diplomática surge um respectivo e inquestionável dever de cumprimento por parte desse Estado ${ }^{21}$.

nacional pode ser contraproducente tendo em conta os interesses da generalidade dos restantes. BAPTISTA, Eduardo Correia-Direito Internacional Público- Sujeitos e responsabilidades, p.202.

${ }^{19}$ Acordo concluído em 27 de fevereiro de 1980, aprovado pelo Regulamento (CEE) no 2213/80 do Conselho.( JO L 226, p. 33; EE 04 F1 p. 132.).Acordo celebrado em 15 de junho de 1979, aprovado pelo Regulamento (CEE) n ${ }^{\circ}$ 2212/80 do Conselho ( JO L 226, p.16; EE 04 F1 p.115).

${ }^{20}$ Processo T-572/93

${ }^{21}$ Como no exemplo do Artigo 14 da Constituição da República Portuguesa. 


\subsection{O Direito de Participação Política Eleitoral e a Responsabilidade por Efeito Direto.}

O direito de participação política eleitoral é reflexo direto da garantia institucional da igualdade de pesos e medidas entre os cidadãos nacionais e residentes comunitários. Ele confere ao cidadão europeu o direito de votar e se candidatar nas eleições autárquicas e para o Parlamento Europeu decorridas no Estado-membro de sua residência ${ }^{22}$.

Antes de Maastricht, porém, alguns dos Estados-membros já conferiam certos direitos de participação política eleitoral a cidadãos nacionais de outros países. Esse era o caso, por exemplo, do direito de participação do estrangeiro nas eleições municipais do Reino da Dinamarca. E também, da previsão italiana que permitia ao cidadão de outro Estado comunitário ser eleito para o Parlamento Europeu através da listagem nacional.

O Tratado da União, portanto, teve a tarefa de lançar o instituto no acervo comunitário enquanto dimensão jurídico-política da Cidadania europeia. ${ }^{23}$ Esse direito, porém, deve ser exercido de acordo com as modalidades adotadas pelo Conselho, deliberando por unanimidade, de acordo com um processo legislativo especial e após consulta do Parlamento Europeu. Essas regras também podem prever disposições derrogatórias, sempre que problemas específicos de um Estado-Membro o justifiquem. A norma comunitária, contudo, não atrela o exercício dos direitos de participação política à adoção das referidas modalidades normativas, fazendo entender que tais circunstâncias não devem interferir na execução do plano comunitário. Ou seja, a falta de conteúdo normativo derivado não será suficiente para afetar o caráter self-executing deste direito, suscetível de ser retirado das disposições convencionais de forma direta. $^{24}$

Porém, a tempestiva da normatização comunitária relativa à matéria dos direitos políticos eleitorais terminou por ceifar prematuramente o aprofundamento das questões

\footnotetext{
${ }^{22}$ Ver artigo $22^{\circ}$ do Tratado sobre Funcionamento da União Europeia.

${ }^{23} \mathrm{O}$ novo conjunto de direitos vem complementar os direitos de participação política já existentes no Estado de que o cidadão é nacional e permitir uma maior integração política, económica e social no Estado de residência. Entre esses direitos encontram-se o direito eleitoral activo e passivo tanto nas eleições para o parlamento (P.E.) como na eleição dos órgãos das autarquias locais. Às eleições directas para o P.E., em prática desde 1979, a partir das listas apresentadas a nível nacional, acrescenta-se a possibilidade dos cidadãos a residir num Estado membro da U.E. de que não são nacionais se apresentaram simultaneamente como candidatos e eleitores nas próprias listas apresentadas pelo Estado de residência. CARDOSO, Carla Pinto et al.-A União Européia- História, Instituições e Políticas,p.62-63

${ }^{24}$ MOURA RAMOS, Rui Manuel- A Cidadania da União...,p.359.
} 
adstritas ao seu caráter auto-executivo. Logo cedo, os Estados-membros tiveram que transpor as Diretivas $94 / 80 / \mathrm{CE}^{25}$ e $93 / 108 / \mathrm{CE}^{26}$ destinadas a harmonizar, respectivamente, as disposições nacionais no sentido de garantir o exercício dos direitos participação política a nível municipal e europeu.

De toda sorte, compreende-se bem que as previsões normativas comunitárias dotadas de suficiente precisão e incondicionamento poderão ser diretamente invocadas por particulares contra o Estado e por particulares contra outros particulares. O que configura a hipótese de efeito direto vertical e de efeito direto horizontal, respectivamente. No caso particular das diretivas, contudo, deve-se saber que haverá apenas a possibilidade do efeito vertical, pois se trata de um ato jurídico caracterizado pela imposição aos Estados de uma obrigação de resultado a ser cumprido dentro dos limites temporais estabelecidos no próprio ato. Nesse sentido, cumpre recordar, a condenação do Tribunal de Justiça ao Reino da Bélgica em face da intempestiva transposição da Diretiva 94/80/CE sob alegação não acatada de implicações de ordem constitucional.

Por fim, deve-se mencionar que a diretiva gera para o Estado-membro uma vinculação imediata ou como restou difundido no Acórdão Wallonie ${ }^{27}$, um dever estatal para "abster-se de adoptar disposições que possam comprometer gravemente o resultado prescrito pela diretiva". É possível, portanto, mensurar o conteúdo sancionável imposto pela situação de incumprimento de uma diretiva munida de efeito direto, assim como na hipótese de transposição incorreta da mesma. E é isso que faz surgir para o particular lesado o direito de invocar juridicionalmente contra o Estado-membro a devida reparação e a desobstrução do benefício. $^{28}$

\footnotetext{
${ }^{25}$ Diretiva de 19/12/1994-JO, L 368 de 31/12/1994.

${ }^{26}$ Diretiva de 06/12/1993-JO, L 329 de 30/12/1993.

${ }^{27}$ Acórdão Inter-Environment Wallonie, de 18/12/1997. Proc. C-129/96

28 "Há que salientar que (...) os particulares têm o direito de invocar as disposições de uma directiva nos tribunais nacionais é porque os deveres que delas decorrem se impõem a todas as autoridades dos Estados-membros. Seria, por outro lado, contraditório entender que os particulares têm o direito de invocar perante os tribunais nacionais, as disposições de uma directiva que preencham as condições acima referidas, com o objetivo de fazer condenar a administração, e, no entanto, entender que esta não tem o dever de aplicar aquelas disposições afastando as de direito nacional que as contrariem. Daqui resulta que, preenchidas as condições exigidas pela jurisprudência do tribunal para as normas de uma directiva poderem ser invocadas pelos particulares perante tribunais nacionais, todos os órgãos da administração, incluindo as entidades descentralizadas, tais como as comunas, têm o dever de aplicar aquelas disposições. Acórdão Fratelli Costanzo. de 22/6/89. Processo 103/88.
} 


\subsection{Direito de Acesso ou Controle Democrático e Responsabilidade Institucional.}

Os direitos de queixa ao Provedor de Justiça e de petição ao Parlamento Europeu têm como objetivo fomentar o acesso e a participação dos sujeitos no funcionamento das instituições comunitárias. Essa norma, porém, afasta-se do paradigma clássico pois também reconhece às pessoas singulares e coletivas com residência ou sede estatutária num Estadomembro a prerrogativa do controle democrático ${ }^{29}$.

Introduzida por Maastricht, a figura do Provedor de Justiça se enquadra na via de intermediação entre os cidadãos e os organismos comunitários, tendo como escopo a investigação e detecção de casos de má administração na aplicação do direito comunitário. Restam excluídos de sua competência, todavia, as disfunções aplicadas pelas administrações nacionais e pelo Tribunal comunitário no exercício de suas funções. Nesses termos, o Provedor de Justiça surge no panorama europeu em harmonia com a tradição francesa, onde o mesmo não tem qualquer direito de ação judicial. Inexiste, assim, competência concorrente entre o Provedor e o Juiz ou mesmo quanto aos demais órgãos comunitários. O que não impede, porém, que a função do provedor seja encarada como uma instância adicional e livre de controle e responsabilização das instituições da União. Esse foi, aliás, o conteúdo da Decisão 94/262/CECA, CE, Euratom relativa ao estatuto e condições gerais para o exercício das funções do Provedor.

Ainda no que se refere à responsabilização institucional, a norma comunitária dispõe que uma vez verificada a má administração do organismo comunitário, o Provedor deverá apresentar o assunto à instituição em causa, que poderá dispor de um prazo de três meses para responder a demanda. Com o fim do inquérito, um relatório final com as recomendações cabíveis deverá ser remetido ao Parlamento Europeu e à instituição, órgão ou organismo em causa. O queixoso, se for o caso, também deverá ser informado do resultado do inquérito ${ }^{30}$.

A constituição excepcional de Comissões Temporárias de Inquérito pelo Parlamento Europeu capacitam, todavia, uma investigação mais genérica sobre situações de má administração na aplicação do direito comunitário. Nesse tipo de controle não há restrição aos

\footnotetext{
${ }^{29}$ Ver artigos $24^{\circ}, 227^{\circ}$ e $228^{\circ}$ do Tratado sobre Funcionamento da União Europeia. Ver também, artigo $11^{\circ}$ do Tratado da União Europeia.

${ }^{30}$ Cf. artigo $228^{\circ}$ do Tratado sobre Funcionamento da União Europeia
} 
casos de responsabilidade institucional, que também pode ser exercida face à administração pública de um Estado-membro ou mesmo sob sujeitos mandatários da comunidade. Nesses termos, compreende-se bem a razão pelo qual o Parlamento Europeu é apontado como um verdadeiro centro de confluência e consagração da defesa graciosa no direito comunitário. Como sabemos, na mesma instituição estão reunidas as Comissões Temporárias de Inquérito, a instituição de Provedor de Justiça, que apesar de independente tem a sua nomeação, sede e orçamento atrelado ao Parlamento e ainda o direito de petição, hoje expressamente descrito no artigo $227^{\circ}$ do Tratado sobre Funcionamento da União. Além do mais, uma vez esgotado o caso concreto e cumprida a tarefa original, todos os mecanismos de controle democrático acabam por confluir suas experiências no próprio Parlamento Europeu. E este, por sua vez, fica com a tarefa de potencializar a intervenção dos referidos órgãos receptores de denúncia através de iniciativas legislativas fortemente legitimadas e demarcadas pela aproximação e maior acesso do cidadão às atividades institucionais da União.

No que se refere propriamente ao direito de petição, cumpre destacar que o regulamento interno do Parlamento Europeu já previa esta prerrogativa no seu artigo $128^{\circ}$. Sendo assim, o Tratado de Maastricht teria apenas avançado na "constitucionalização" do tema. O que foi posteriormente ampliado pelo Tratado de Amsterdã, que conferiu aos cidadãos comunitários o direito de se dirigir por escrito, numa das línguas previstas no Tratado, a qualquer das instituições ou organismos comunitário e obter uma resposta redigida neste mesmo idioma. ${ }^{31}$

Convém salientar, entretanto, que a análise das petições pelo Parlamento Europeu não poderá exceder o âmbito de sua própria competência, em harmonia com requisito do equilíbrio institucional e da independência do poder judicial comunitário. Nesses termos, fica vetada a intromissão na competência de outras instituições quando do exercício da prerrogativa pelo Parlamento, que também não poderá analisar petições que envolvam fato objeto de processo judicial ou que ponham em causa o fundamento de decisão.

\footnotetext{
${ }^{31}$ Este direito foi ampliado pelo Tratado de Amsterdã, no qual, qualquer cidadão da União pode dirigir-se por escrito a qualquer das Instituições ou Órgão Comunitários, ou seja, ao Parlamento Europeu, ao Conselho, à Comissão, ao Tribunal de Justiça e ao Tribunal de Contas, e obter resposta redigida na mesma língua.(...) Este direito demonstra a necessidade de aproximar o cidadão das Instituições e dos Órgãos Comunitários, permitindolhes conhecer, de forma direta a opinião do cidadão. STELGELS, Isabela Kathrin-A Cidadania da União Européia-Uma sugestão para o Mercosul, p.52.
} 


\section{II - Considerações finais}

Após uma breve introdução do conceito de Cidadania no acervo comunitário analisamos individualmente cada uma de suas prerrogativas fazendo menção expressa ao conteúdo da responsabilidade inerente. Assim, o problema da falta de efeito direto foi apresentado como anteparo ao tema da responsabilização do Estado-membro por não cumprimento de norma comunitária. No mesmo sentido, a questão da auto-execução permeou a discussão em torno da responsabilidade estatal em face de não transposição de diretiva. De uma forma mais incidente, o debate sobre a proteção diplomática terminou por destacar os aspectos que irresponsabilizam a União enquanto entidade garantidora e efetivadora deste direito. E finalmente, o estudo dos direitos de acesso aos organismos comunitários acabou por revelar muito mais acerca do controle e da responsabilização institucional.

Nesse sentido, mais do que uma mera compilação de idéias e considerações sobre a temática da responsabilidade, este trabalho revela a tendência doutrinária para uma avaliação macroscópica do assunto, visualizando a responsabilidade enquanto ética necessária e solidária destinada a intensificar o instituto da personalidade.

Assim, na via contrária ao processo de "diminuição" ou "regionalização" do mundo, a Responsabilidade se expande, revelando-se como a mais emblemática expressão de juridicidade permeada ao direito interno e principalmente ao ordenamento Comunitário, onde as necessidades de garantia se fazem urgentes.

\section{Referências bibliográficas}

BAPTISTA, Eduardo Correia. Direito Internacional Público.Vol.II,Coimbra:Almedina, 2004.

CAMPOS, João Mota et. al. Manual de Direito Comunitário.Lisboa:FCG,4 ed., 2004.

CARDOSO, Carla Pinto et al. A União Européia: História, Instituições e Políticas. Porto: Universidade Fernando Pessoa, 2006. 
CLOSA, "The Concept of citizenship in the Treaty on European Union". in: Commom Market Law Revew, 29, 1992.

CUNHA et al. História do Direito- Do Direito romano à Constituição Européia.Coimbra:Almedina, 2005.

DINAN, Desmond. Origins and Evolution of the European Union. Oxford:Oxford University Press.2006.

DUARTE, Maria Luísa. Estudos de Direito da União e das Comunidades Européias-Direito Comunitários Institucional, União Européia e Constituição, Direito Comunitário Material. Coimbra:Coimbra Editora, 2000.

FERNANDES, Antônio José. Direitos Humanos e Cidadania Européia (fundamentos e dimensões).Coimbra:Almedina, 2004.

GORJÃO-HENRIQUES, Miguel. Direito Comunitário.3 ed. Coimbra: Almedina, 2005.

KOVAR/SIMON. La Citoyenneté européene, in:Cahiers de Droit Européen. 29 (1993/3/4).

MACHADO, Jónatas E.M. Direito Internacional-do paradigma clássico ao pós-11 de setembro. 2 ed.Coimbra: Coimbra Editora,2004.

MARTINS, Ana Maria Guerra. Curso de Direito Constitucional da União Européia.Coimbra: Almedina, 2004.

MOLINA DEL POZO, Carlos Francisco. Manual de Derecho de la Comunidad Europea. 3 ed.,Madrid:Trivium, 1997.

MOLLE, Willem. The Economics of European Integration: Theory, Practise, Policy.4 ed.Aldershot:Ashgate,2001. 
MONGIARDIM, Maria Regina. Diplomacia. Coimbra:Almedina,2007.

MOREIRA, Adriano. Europa em Formação- A crise do atlântico. 4 ed.Lisboa:Instituto Superior de Ciências Sociais e Políticas, 2004.

MOURA RAMOS, Rui Manuel Gens de. Da Comunidade Internacional e do seu DireitoEstudos de Direito Internacional Público e Relações Internacionais. Coimbra:Coimbra Editora, 1996.

MOURA RAMOS, Rui Manuel Gens. "A cidadania da União:caracterização, conteúdo e desenvolvimento" in Revista de Legislação e Jurisprudência. Ano 135, n. 3939,Coimbra: Comibra Editora, julho- agosto de 2006.

MOURA RAMOS, Rui Manuel. Das Comunidades à União Européia.Estudos de Direito Comunitário. 2 ed.Coimbra:Coimbra Editora, 1999.

PÉREZ-BUSTAMANTE, Rogelio et al. História da União Européia. Coimbra:Coimbra Editora, 2004.

PITTA e CUNHA, Paulo. Integração Européia-Estudos de Economia, Direito e Política Comunitários-1963-1993. 2 ed.Coimbra:Almedina, 2004.

POND, Elizabeth. O Renascer da Europa.Trad. Paulo Emílio Pires, Lisboa:Ulisseia.2005.

PORTO, Manuel Carlos Lopes. Teoria da Integração e Políticas Comunitárias. 3 ed. Ampliada e actualizada, Coimbra: Almedina, 2001.

QUADROS, Fausto de. Direito da União Européia-Direito Constitucional e Administrativo da União Europeia. Coimbra: Almedina, 2004. 
RIBEIRO, Maria Manuela Tavares. A idéia de Europa-Uma perspectiva histórica. Coimbra:Quarteto Editora,2003.

RIBEIRO, Maria Manuela Tavares. "Multiculturalismo ou coabitação cultural?" in: Identidade Europeia e Multiculturalismo. Coimbra: Quarteto, 2002.

SOARES, António Goucha. A União Européia.Coimbra:Almedina,2006.

STELGES.Isabela Kathrin. A Cidadania da União Européia-Uma Sugestão para o Mercosul. Belo Horizonte: Del Rey, 2002. 